\title{
Semi-actively Implemented Non-linear Damping for Building Isolation Under Seismic Loadings
}

\author{
Yun-Peng Zhu ${ }^{1}$, Zi-Qiang Lang ${ }^{1 *}$, Yosuke Kawanishi ${ }^{2}$ and Masayuki Kohiyama ${ }^{3}$ \\ ${ }^{1}$ Department of Automatic Control and Systems Engineering, University of Sheffield, Sheffield, United Kingdom, ${ }^{2}$ Formerly, \\ Graduate School of Science and Technology, Keio University, Hiyoshi, Japan, ${ }^{3}$ Department of System Design Engineering, \\ Keio University, Hiyoshi, Japan
}

\section{OPEN ACCESS}

Edited by: Luigi Di Sarno, University of Sannio, Italy

Reviewed by:

Dario De Domenico, University of Messina, Italy Kohei Fujita,

Kyoto University, Japan Miao Yu,

Chongqing University, China

${ }^{*}$ Correspondence:

Zi-Qiang Lang

z.lang@sheffield.ac.uk

Specialty section:

This article was submitted to

Earthquake Engineering,

a section of the journal Frontiers in Built Environment

Received: 13 October 2019 Accepted: 11 February 2020 Published: 26 February 2020

Citation:

Zhu Y-P, Lang Z-Q, Kawanishi Y and Kohiyama M (2020) Semi-actively Implemented Non-linear Damping for Building Isolation Under Seismic Loadings. Front. Built Environ. 6:19 doi: 10.3389/fbuil.2020.00019
It is well-known that semi-active solution can achieve building isolation with much less energy requirements than active solutions. Also, it has been shown in previous studies that compared to linear damping, non-linear damping performs better for building isolation under sinusoidal ground motions. The present study is concerned with the extension of the application of the semi-actively implemented non-linear damping to building isolation under seismic loadings. A two-degree-of-freedom (2-DOF) scaled building model is used for simulation studies. Experimental tests on a physical building model have been used to validate the effectiveness of the 2-DOF scaled building model in representing the behaviors of a physical building structure. The optimal design of the semi-actively implemented non-linear damping for building isolation under design seismic motions is then carried out using the 2-DOF scaled building model based on simulation studies. The results show that an optimal design of semi-actively implemented non-linear damping can improve the performance of building isolation under design seismic motions in terms of both absolute acceleration and inter-story drift.

Keywords: building, isolation, semi-active, non-linear damping, seismic loadings

\section{INTRODUCTION}

Building isolation systems are important for protecting buildings during earthquakes (Fujita et al., 2016; Hayashi et al., 2018). Traditional building isolation systems are designed using low horizontal-stiffness bearings to achieve low resonant frequencies so as to isolate earthquake loadings over a wide range of frequencies (Naeim, 1989). However, during some recent earthquakes, e.g., the 2011 Tohoku earthquake in Japan, long period ground motion with low frequencies were recorded, which was close to the resonance frequencies of some high-rise and base-isolated buildings (Takewaki et al., 2011; Kasai et al., 2013), indicating that traditional solutions may not provide desired isolation performance in these cases. Although some traditional isolation devices such as tuned mass damper (TMD) (Taniguchi et al., 2008) or enhanced variants with the inerter as tuned mass damper inerter (TMDI) (De Domenico et al., 2019) have been discussed and applied in building isolation systems, expensive costs, and sensitive adjustment to the dynamic property are required in these devices of a constructed building (Dan and Kohiyama, 2013).

The vibration around the resonant frequencies can be reduced by introducing a linear damping into the building isolation system, but this can be detrimental to the building isolation over non-resonance frequency ranges (Soong, 1990; Amini et al., 2015). Large supplemental damping combined with seismic isolation is detrimental because it increases the higher-mode response, thus 
having a negative effect on the superstructure acceleration and inter story drift (Kelly, 1999; De Domenico and Ricciardi, 2018). To resolve this issue, many active control techniques including the actively implemented Linear-quadratic- Gaussian (LQG) control (Liu and Wu, 2013; Wang and Dyke, 2013) have been applied to improve the building isolation performance. However, the active control techniques require large power supply and high maintenance cost (Sims et al., 1999), and the stability of the actively controlled building isolation system would also be a concern (Taniguchi et al., 2016). Recently, it has been shown that these problems can be circumvented by using a non-linear damping based isolator that can reduce transmitted vibrations over both resonant and non-resonant frequencies (Peng et al., 2010, 2011; Guo et al., 2012; Lang et al., 2013). For example, Peng et al. $(2010,2011)$ has shown that non-linear damping can reduce the force transmissibilities over all frequency ranges of concern for both single-degree-of-freedom (SDOF) and multi-degree-of-freedom (MDOF) systems subject to sinusoidal loadings.

In practice, a non-linear damping can be realized by using, e.g., viscous fluid dampers or friction dampers, to dissipate seismic energies for building isolation (Symans et al., 2008). However, these are usually difficult to design and implement in practice to achieve a desired damping characteristic, and a semi-active solution is considered to be an ideal solution to this problem (Guyomar and Badel, 2006; Ebrahimi et al., 2008; Laalej et al., 2012; Weber, 2014; Ho et al., 2018). For example, Laalej et al. (2012) studied the use of an MR (Magneto-Rheological) damper in an isolation system to semi-actively implement the power law non-linear damping characteristics. Ebrahimi et al. (2008) investigated the implementation of non-linear vibration absorbers using the eddy current damper.

The properties of the semi-actively implemented non-lineardamping-based building isolation system have been investigated by the authors for the cases where the seismic loadings are sinusoidal (Weber, 2014). The results indicated that the nonlinear damping can provide a desired isolation performance under sinusoidal loadings. However, in practice, the seismic loadings are usually complex bandwidth or random signals, where different frequencies are interacted in the isolation system. It is significant to clarify the isolation performance of semi-active control damping subject to seismic loadings before applying the device into a building system. In the present study, the work will be extended to investigate the design and semi-active implementation of non-linear damping for building isolation under seismic loadings.

The paper is organized as follows. The performance of a semi-actively implemented non-linear-damping-based building isolation system for a laboratory physical building model under sinusoidal loadings is analyzed in section The Nonlinear Damping-Based Semi-active Building Isolation System. Then, in Section Design of Non-linear Damping-Based Building Isolation System Under Seismic Ground Motions, the extension of the application of the non-linear damping technique to the cases where the building model is subject to seismic ground motions is investigated. Finally, conclusions are reached in section Conclusions.

\section{THE NON-LINEAR DAMPING-BASED SEMI-ACTIVE BUILDING ISOLATION SYSTEM}

\section{A Scaled 2-DOF Building Model With a Semi-active Isolator}

In laboratory studies, in order to investigate the performance of a building isolation system, the building system is often simplified to a mass-stiffness-damping MDOF system and then further scaled down to a 2-DOF system as shown in Figure 1 (Wang and Dyke, 2013; Amini et al., 2015; Hayashi et al., 2018; Ho et al., 2018), where the lower and upper masses represent the floor slab above the isolation layer and the superstructure of the target building, respectively. In Figure 1, $m_{1}$ and $m_{2}$ are the masses of the 2-DOF system, $k_{1}$ and $k_{2}$ are the stiffness parameters, $c_{1}$ and $c_{2}$ are damping parameters, $x_{1}$ and $x_{2}$ are the 1 st and 2 nd floor displacements relative to the ground motion $z$, respectively.

The 2-DOF building system is protected by a semi-active isolator producing a damping force determined by the ground motion acceleration $\ddot{z}$ and the first floor displacement $x_{1}$. The motion equation of the 2-DOF system with this semi-active isolator can be written as

$$
M \ddot{x}+C \dot{x}+K x=E u_{\text {con }}+F \ddot{z}
$$

where

$$
\begin{aligned}
& x=\left[x_{1}, x_{2}\right]^{\mathrm{T}} ; \boldsymbol{M}=\left[\begin{array}{cc}
m_{1} & 0 \\
0 & m_{2}
\end{array}\right] ; \boldsymbol{C}=\left[\begin{array}{cc}
c_{1}+c_{2} & -c_{2} \\
-c_{2} & c_{2}
\end{array}\right] \\
& \boldsymbol{K}=\left[\begin{array}{cc}
k_{1}+k_{2} & -k_{2} \\
-k_{2} & k_{2}
\end{array}\right] ; \boldsymbol{E}=[1,0]^{\mathrm{T}} ; \boldsymbol{F}=\left[-m_{1},-m_{2}\right]^{\mathrm{T}}
\end{aligned}
$$

and $u_{\text {con }}=F_{d}\left(x_{1}\right)$ represents the damping force produced by the semi-active isolator, $F_{d}\left(x_{1}\right)$ is a function dependent on $x_{1}$.

\section{The Non-linear Damping-Based Semi-active Isolator}

Consider the case where the semi-active isolator is implemented by a linear damper with three variable coefficients $c_{p 1}, c_{p 2}$

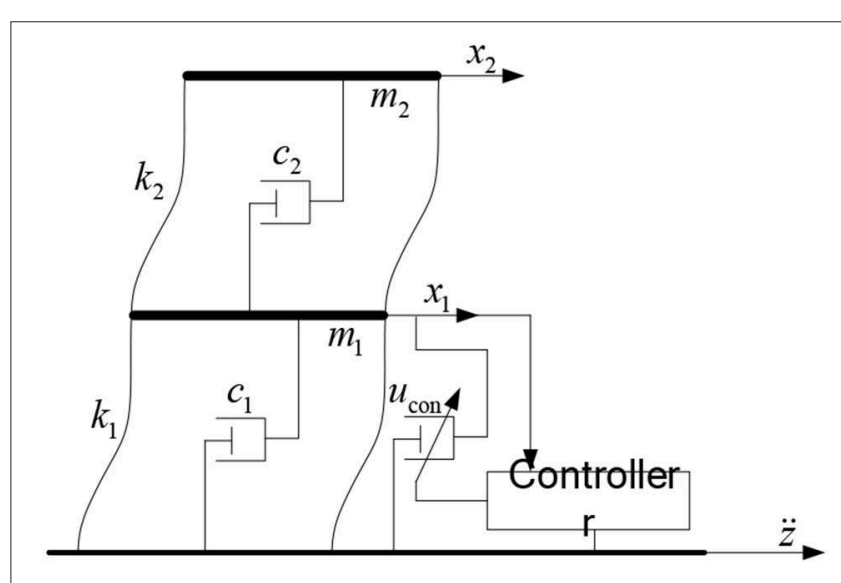

FIGURE 1 | The scaled 2-DOF building model. 
and $c_{p 3}$ as shown in Figure 2. The maximum damping $c_{p 3}$ is realized by closing the bottom valve and opening the top valve, the middle damping $c_{p 2}$ is obtained by closing the top valve and opening the bottom valve, and the minimum damping $c_{p 1}$ is generated by opening both the bottom and top valves. In addition, the damping force from the isolator is produced such that:

$$
u_{\mathrm{con}}=F_{d}\left(x_{1}\right)=-c_{s}(t) \dot{x}_{1}
$$

where

$$
c_{s}(t)= \begin{cases}c_{p 1}, & \text { for } u_{d} / \dot{x}_{1} \leq\left(c_{p 1}+c_{p 2}\right) / 2 \\ c_{p 2}, & \text { for }\left(c_{p 1}+c_{p 2}\right) / 2<u_{d} / \dot{x}_{1} \leq\left(c_{p 2}+c_{p 3}\right) / 2 \\ c_{p 3}, & \text { for } u_{d} / \dot{x}_{1}>\left(c_{p 2}+c_{p 3}\right) / 2\end{cases}
$$

and $u_{d}$ is the desired damping force.

Figure 3A shows the MATLAB Simulink realization of a nonlinear damping-based semi-active isolator where the desired force $u_{d}$ is determined as a power law damping such that $u_{d}=-c_{n 3} \dot{x}_{1}^{3}$ with $c_{n 3}$ being the non-linear damping coefficient. The dynamics of the semi-active isolator is modeled by the first order transfer function $(T s+1)^{-1}$ where $T$ is the time constant of the transfer function and $s$ is the variable in the Laplace transform. The damping force $u_{\text {con }}$ is produced to achieve the objective of $u_{d}=-c_{n 3} \dot{x}_{1}^{3}$ by computing the selected $c_{n 3} v^{2}$ value, which are either $c_{p 1}, c_{p 2}$ or $c_{p 3}$, times the velocity $v$. Figure $3 \mathbf{B}$ shows how an increase of the power law damping coefficient $c_{n 3}$ from $c_{n 3,1}$ to $c_{n 3,2}$ to $c_{n 3,3}$ can approximately be realized by a switch between $c_{p 1}, c_{p 2}$ and $c_{p 3}$ to produce an approximate of different cubic damping forces $u_{\text {con, } 1}, u_{\text {con, } 2}$ and $u_{\text {con, } 3}$, respectively. In practice, due to the mechanics of the semi-active damping device which is modeled by $(T s+1)^{-1}$, the changing of the damping coefficients will not be a bump like Figure 3B, and will gradually shift between different damping coefficients.

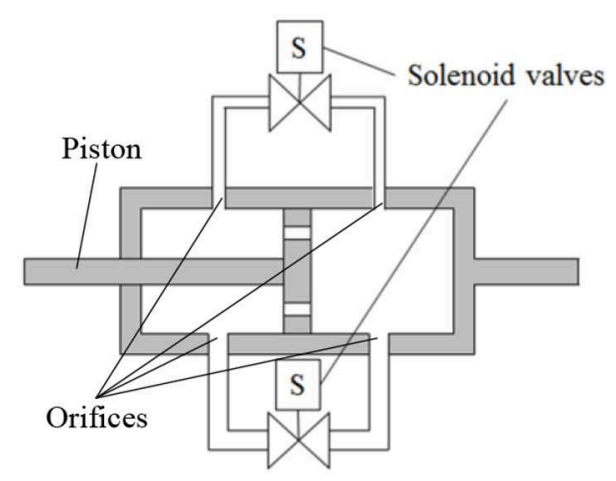

FIGURE 2 | Schematic illustration of a semi-active isolator.

\section{Performance Under Sinusoidal Ground Motions}

It has been shown in Lang et al. (2013) and Ho et al. (2018) that, under a sinusoidal ground motion given by:

$$
\ddot{z}=A \sin (2 \pi f t)
$$

with $A$ and $f$ are excitation magnitude and frequency in $\mathrm{ms}^{-2}$ and $\mathrm{Hz}$, respectively, by using an appropriate non-linear dampingbased semi-active isolator, the force transmissibility defined by Lang et al. (2013) and Ho et al. (2018).

$$
T_{s}(f)=\frac{\left|F\left\{\ddot{x}_{i}+\ddot{z}\right\}\right|_{\omega=2 \pi f} \mid}{A}, i=1 \text { or } 2
$$

can be significantly reduced over both the resonant and nonresonant frequency ranges of the building system. In (5), $F\{$. $\}$ denotes the Fourier transform operation.

For example, the parameters of a 2-DOF building model obtained by scaling down the 10-story Sosokan building model at Keio University in Japan are:

$$
\begin{aligned}
m_{1} & =3.672 \mathrm{~kg}, m_{2}=1.696 \mathrm{Kg} ; \\
k_{1} & =1036 \mathrm{~N} / \mathrm{m}, k_{2}=5868.7 \mathrm{~N} / \mathrm{m} ; \\
c_{1} & =0.0856 \mathrm{Ns} / \mathrm{m}, c_{2}=0.5367 \mathrm{Ns} / \mathrm{m} ;
\end{aligned}
$$

Consider the case where the three coefficients of the linear damper that implements the semi-active isolator are designed as:

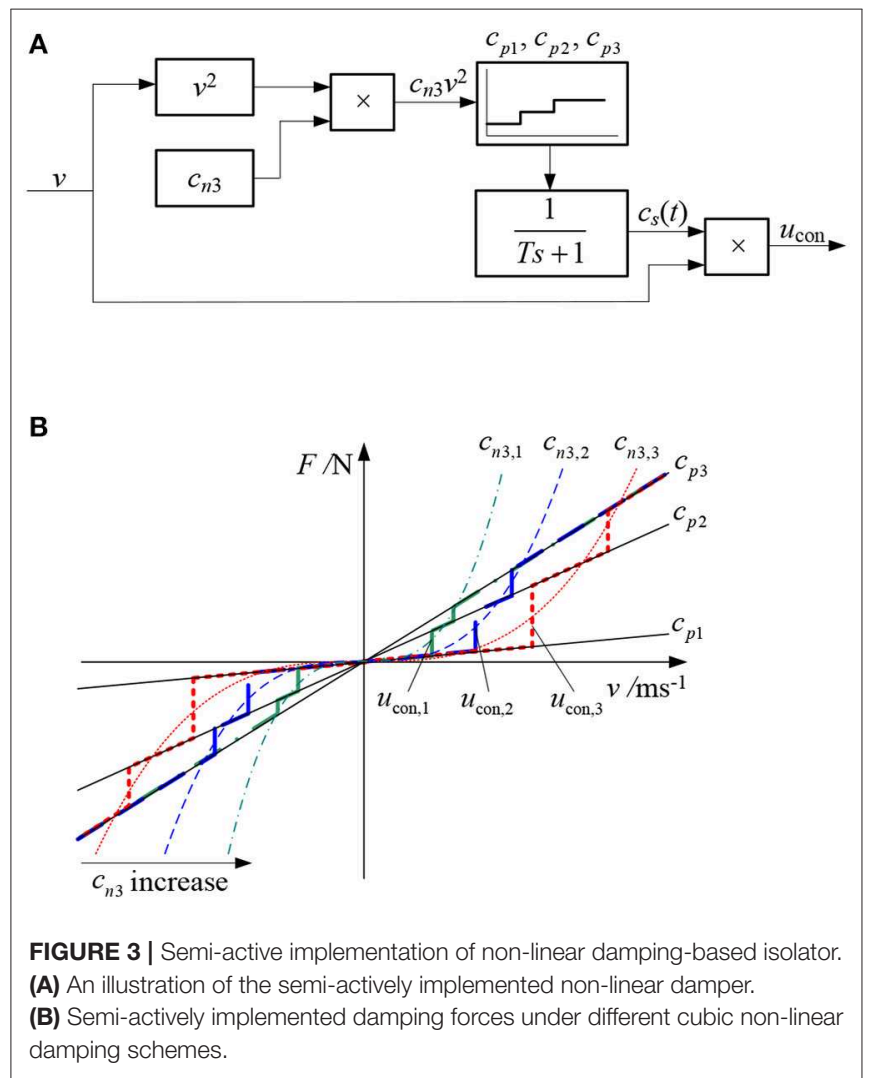




$$
c_{p 1}=4.76 \mathrm{Ns} / \mathrm{m} ; c_{p 2}=39.8 \mathrm{Ns} / \mathrm{m} ; c_{p 3}=55.9 \mathrm{Ns} / \mathrm{m}
$$

and the time constant with the damper is $T=0.155 \mathrm{~s}$ (Nakamichi, 2018).

The transmissibility (5) on the first floor of the 2-DOF building model under sinusoidal input (4) with $A=1 \mathrm{~ms}^{-2}$ and $f \in(0,15] \mathrm{Hz}$ is shown in Figure 4, indicating the isolation performance under the non-linear damping-based semi-active isolator with $c_{n 3}=3 \times 10^{4} \mathrm{Ns}^{3} / \mathrm{m}^{3}$ and the performance under three linear damping-based semi-active isolators with $c_{s}(t)=$ $c_{p 1}, c_{p 2}$ and $c_{p 3}$, respectively.

From Figure 4, the advantage of non-linear damping over linear damping when the building system is subject to harmonic loadings can clearly be observed. These phenomena have been investigated in the previous studies (Lang et al., 2013) but there is still no result on the performance of the non-linear dampingbased semi-active building isolation system when the system is subject to seismic ground motions.

In the following, the design and evaluation of the non-linear damping-based semi-active building isolation system will be

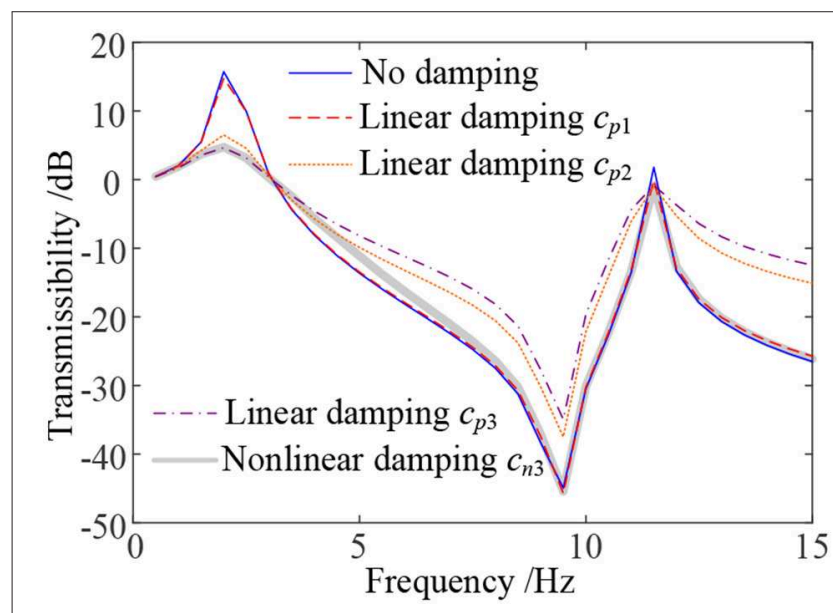

FIGURE 4 | Force transmissibility under linear and non-linear damping-based semi-active isolators. extended to the case of a 2-DOF laboratory building model subject to seismic ground motion loadings.

\section{DESIGN OF NON-LINEAR DAMPING-BASED BUILDING ISOLATION SYSTEM UNDER SEISMIC GROUND MOTIONS}

\section{Comparison of the Output Response of the 2-DOF System and the Response of a Laboratory Physical Building Model to Seismic Ground Motions}

Generally speaking, the seismic ground motions are random signals that contain a wide band of frequencies.

In this study, two different seismic waves including the hardsoil-layer (Type 1) and soft-soil-layer (Type 2) ground motions are considered. The time histories of the two ground motions that can be recorded in practice are produced according to different design response spectra shown in Figure 5A, where the waves were scaled down in the experiment by the scaling factor $\lambda_{t}=$ $1 / 5$ to the sampling time and $\lambda_{m}=5$ to the magnitude as shown in Figure 5B.

A 2-DOF building model test rig is shown in Figure 6, where the first floor velocity $\dot{x}_{1}$ is used to control the semi-active isolator with $\dot{x}_{1}$ estimated by a Kalman filter using the measured acceleration data $\ddot{z}, \ddot{x}_{1}$ and $\ddot{x}_{2}$ (Dan et al., 2015; Nakamichi, 2018; Kohiyama et al., 2019). The parameters of the physical building model and the semi-active isolator are given in Equations (6) and (7), respectively. Therefore, the test rig is a 2-DOF scaled down physical model of the Sosokan building.

The semi-active control damper is shown in Figure 7A, where the structure of internal electromagnetic valve is demonstrated in Figure 7B (Nakamichi, 2018). The linear damping coefficient $c_{p 1}$ is achieved when two valves open, $c_{p 2}$ is achieved when one valves open, and $c_{p 3}$ is achieved when all valves close. Specifications of the damper and controller are listed in Table 1.

Figure 8 shows the switch-overs between the three different damping coefficients during the model simulation and experimental test on the 2-DOF scaled down building model,
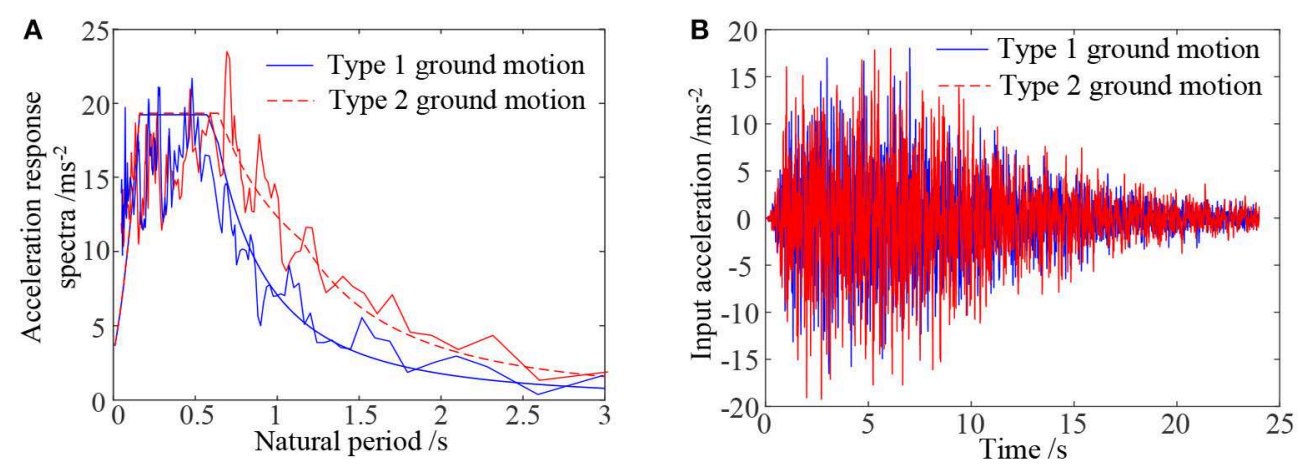

FIGURE 5 | The response spectra and corresponding time histories of seismic ground motions. (A) The response spectra of ground motions. (B) Scaled seismic ground motions. 
respectively. Both the model simulation and experimental test are undertaken under Type 1 ground motion in Figure 5A with the coefficient of non-linear damping to be implemented chosen as $c_{n 3}=3 \times 10^{4} \mathrm{Ns}^{3} / \mathrm{m}^{3}$. Figure 8 shows the comparison of the simulated and experimentally obtained building acceleration responses on the first floor.

It can be seen from Figures 8, 9 that the simulation results are basically consistent with experimental ones, indicating that the 2DOF system (6) and (7) can well represent the laboratory physical building model for the analysis and design of a semi-active building isolation system.

\section{System Analysis and Design}

Consider the 2-DOF scaled down building model with parameters given by Equation (6) and the semi-active isolator

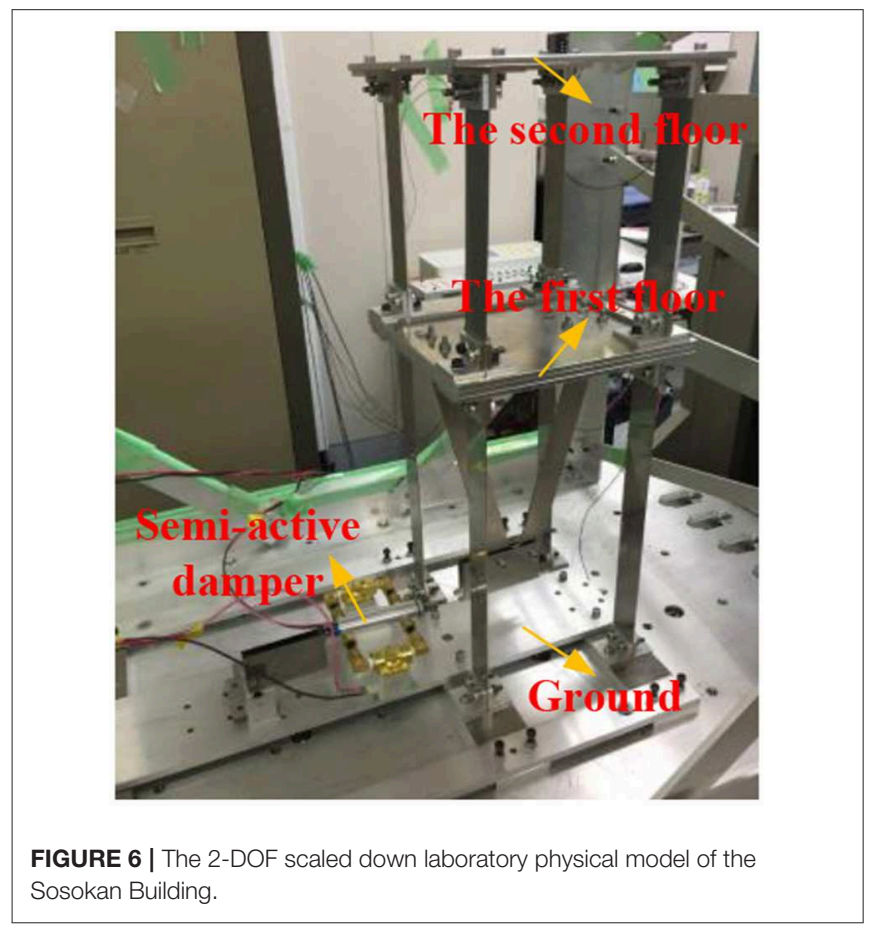

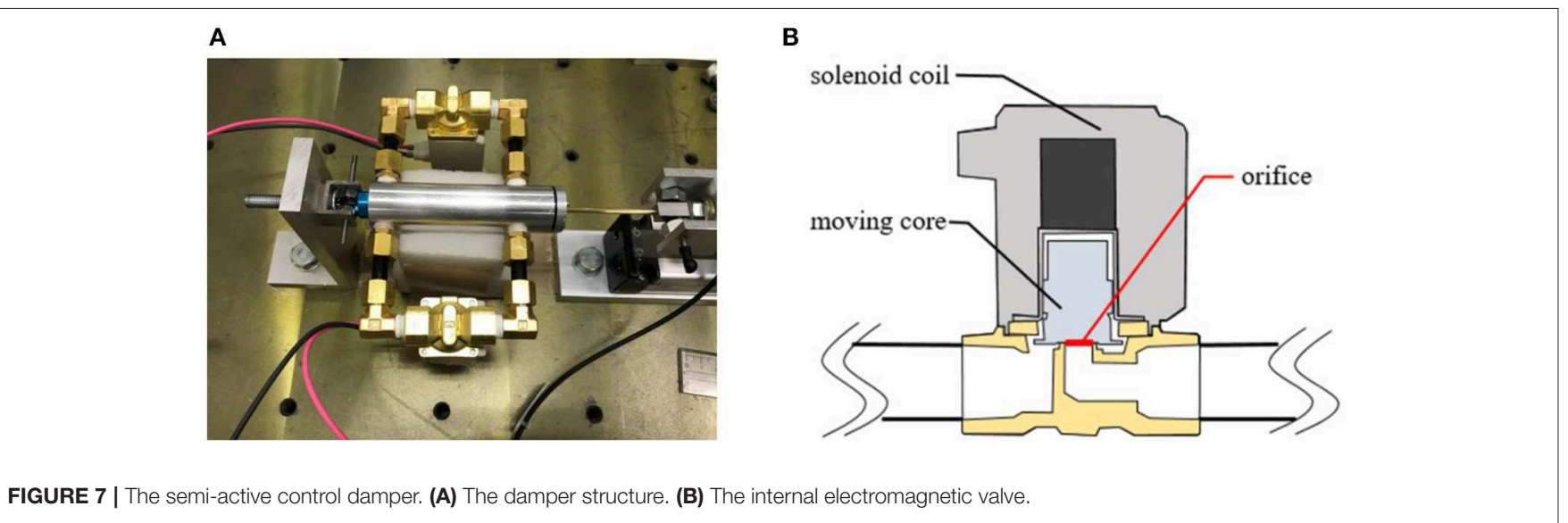

with three switchable damping parameters given by Equation (7). The responses of the building model to the two seismic ground motions in Figure 5B are obtained by simulation studies. Figure 9 shows the maximum of the absolute acceleration and inter-story drift on the first and second floor, respectively. The results are obtained when Type 1 ground motion is applied and non-linear damping coefficients implemented by the semi-active isolator are varied over the range of $c_{n 3} \in[0,10] \times 10^{4} \mathrm{Ns}^{3} / \mathrm{m}^{3}$. In addition, the responses of the building model under three

TABLE 1 | The specification of the semi-active control damper.

\begin{tabular}{lc}
\hline Specification & Value \\
\hline Damper & \\
Maximum stroke & $\pm 27.5 \mathrm{~mm}$ \\
Mass & $0.90 \mathrm{~kg}$ \\
Electromagnetic valve & \\
Diameter of orifice & $2 \mathrm{~mm}$ \\
Mass & $0.300 \mathrm{~kg}$ \\
Maximum working pressure difference & $0.6 \mathrm{MPa}$ \\
Rated voltage & $24 \mathrm{~V}$
\end{tabular}

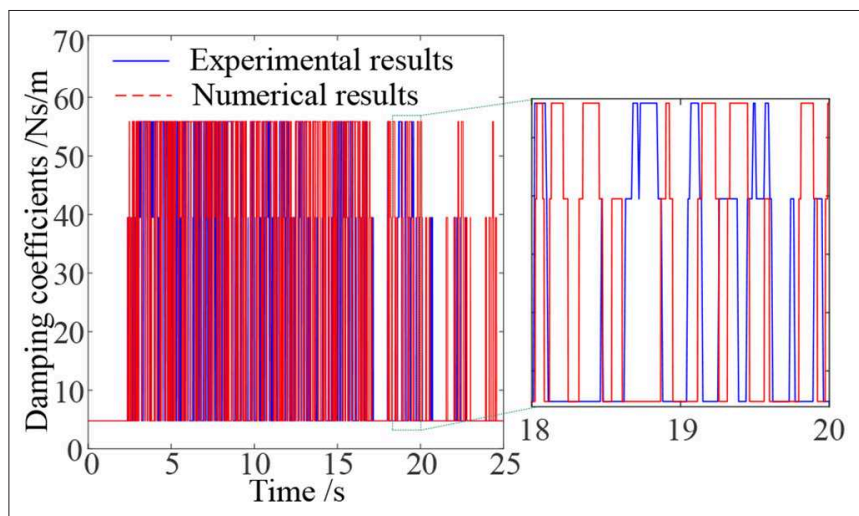

FIGURE 8 | Switch-overs of damping coefficients with semi-active isolator. 
linear damping-based isolations are also obtained and shown in Figure 9 for a comparison.

It can be seen from Figure $\mathbf{1 0}$ that, an increase of linear damping can reduce the maximum inter-story drift, but may increase the maximum of absolute accelerations. However, by using non-linear damping implemented by semi-active isolator, an optimal design for $c_{n 3}$ can be reached such that a desired isolation performance in terms of both maximum absolute accelerations and inter story drift can be achieved.

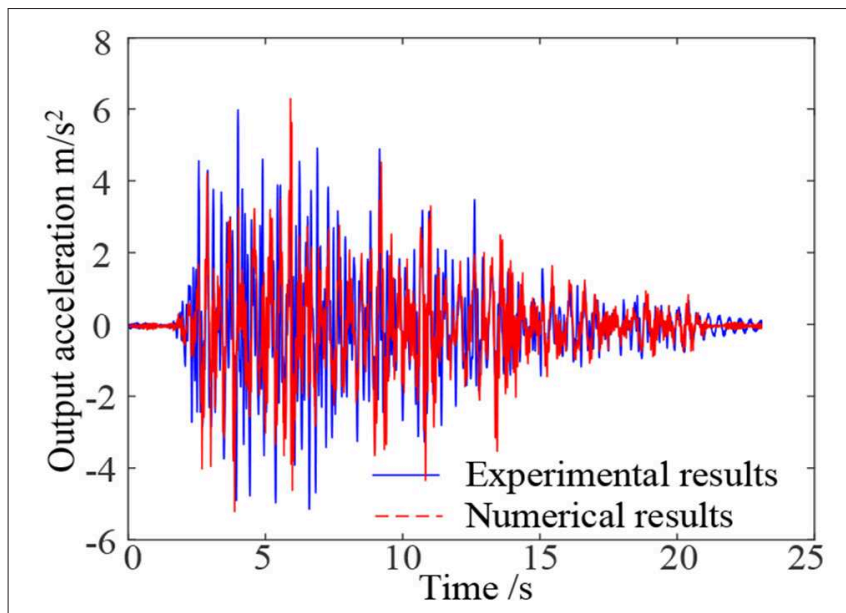

FIGURE 9 | Acceleration responses.
Figure 11 shows the same performance of the non-linear/linear damping based semi-active building isolation system but under Type 2 ground motion. Obviously, a conclusion about the optimal design of $c_{n 3}$ similar to that reached from Figure 10 can be obtained.

Based on these observations, it is possible to find a non-linear damping parameter $c_{n 3}$ to achieve desired isolation performance including both the acceleration and displacement of all floors. The desired isolation performance is defined by the designer. For example, the issue of optimal design of non-linear damping parameter $c_{n 3}$ can be formulated under Type 1 ground motion as follows:

Find a non-linear damping coefficient $c_{n 3}=\bar{c}_{n 3}$, such that:

$$
\bar{c}_{n 3}=\max \left\{c_{n 3}\right\}
$$

subject to the constraint.

$$
\left\{\begin{array}{l}
\max \left(\left|\ddot{x}_{1}+\ddot{z}\right|\right) \leq 6.17 \mathrm{~m} / \mathrm{s}^{2} ; \max \left(\left|x_{1}\right|\right) \leq 0.019 \mathrm{~m} \\
\max \left(\left|\ddot{x}_{2}+\ddot{z}\right|\right) \leq 9.86 \mathrm{~m} / \mathrm{s}^{2} ; \max \left(\left|x_{2}\right|\right) \leq 0.021 \mathrm{~m}
\end{array}\right.
$$

The above design problem is to find the maximum value of the non-linear damping coefficient that satisfy the acceleration and displacement requirement (9). It is worth noting that the constraint (9) is only used to illustrate the design process and in practice, the optimized result may not be achieved when an inappropriate constraint is applied.
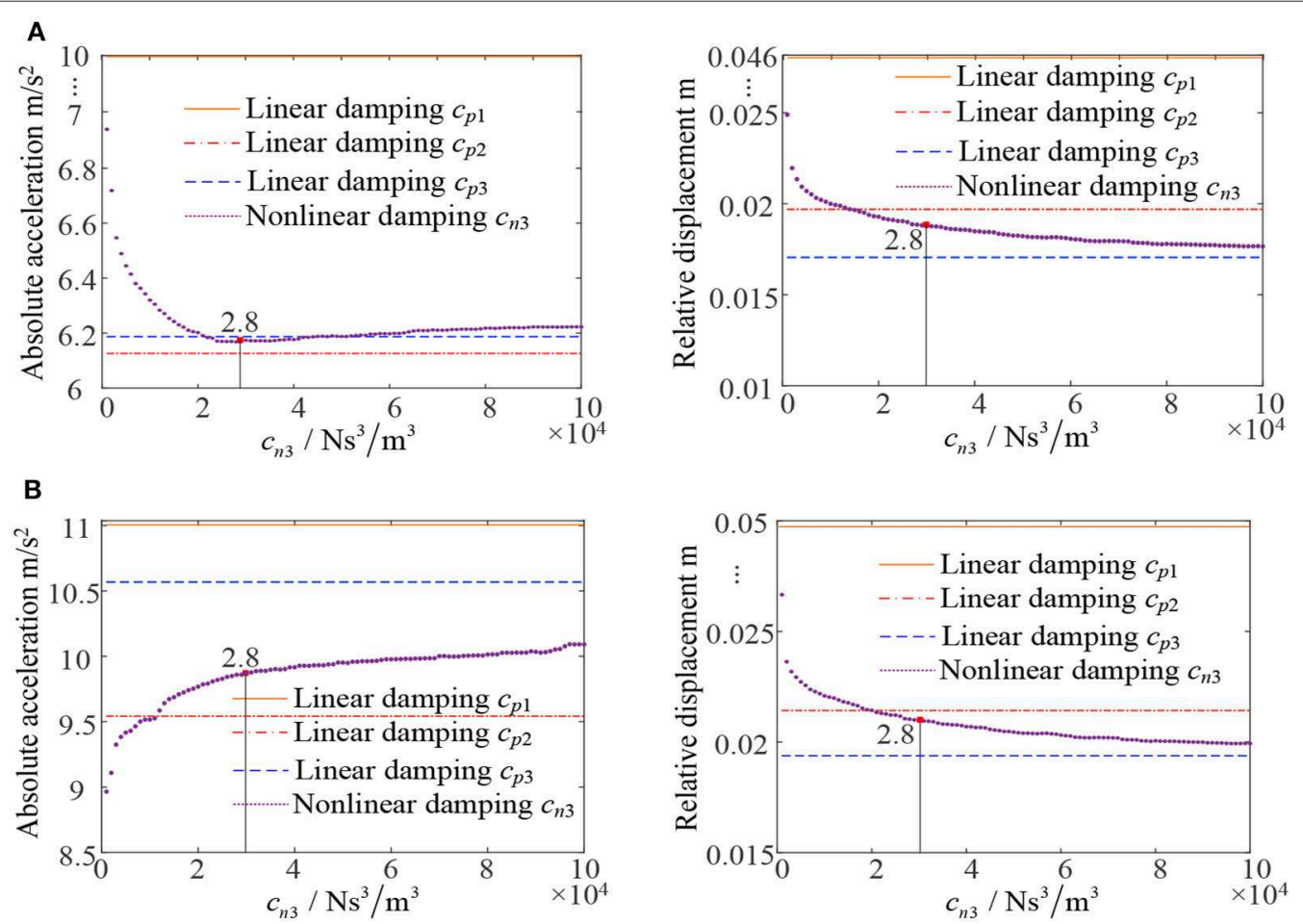

FIGURE 10 | Maximum output acceleration and inter-story drift under Type 1 ground motion. (A) Absolute acceleration and inter-story drift of the first floor. (B) Absolute acceleration and inter-story drift of the second floor. 

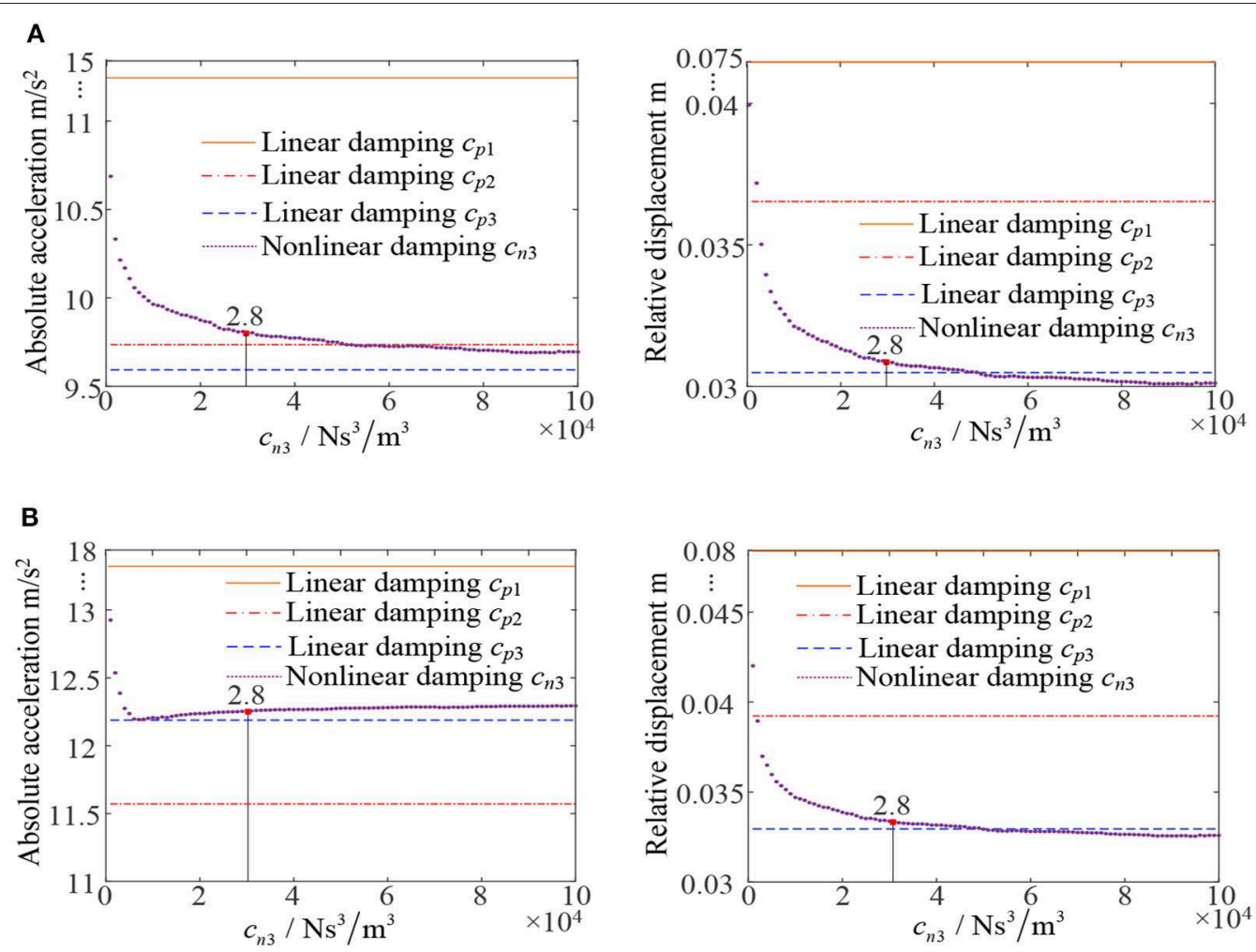

FIGURE 11 | Maximum output acceleration and inter-story drift under Type 2 ground motion. (A) Absolute acceleration and inter-story drift of the first floor. (B) Absolute acceleration and inter-story drift of the second floor.

The optimal design can be numerically achieved as:

$$
c_{n 3}=2.8 \times 10^{4} \mathrm{Ns}^{3} / \mathrm{m}^{3}
$$

which is illustrated in Figures 10, 11.

It can be seen from Figures 10, 11 that, by using the optimal design (10) so as to satisfy the design requirement under Type 1 ground motion, an ideal maximum absolute acceleration and inter-story drift can also be achieved when the building system is subject to loadings represented by Type 2 ground motion.

\section{CONCLUSIONS}

The semi-active non-linear-damping-based building isolation has previously been introduced under sinusoidal ground motions to achieve low force transmissibilities over the whole frequency range of concern. However, most seismic loadings in practice are bandwidth and random signals, which are more complex than the sinusoidal loading case and there is not much researches focused on the application of semi-active damping isolation system in these scenarios before. In the present study, the base isolation under seismic ground motions and the design of the semi-active base isolation system have been studied to extend the application of the semi-active non-linear damping-based building isolation to more complicated scenarios.

A 2-DOF building model, which is a scaled down representation of the Sosokan building in Keio University in Japan, is used for the analysis and design of the semi-active non-linear damping-based building isolation system under seismic loadings. Both the acceleration and the inter-story drift of the building model have been taken into account. An optimal design of the non-linear damping parameter has been achieved numerically.

The present study shows that a desired building isolation performance under seismic loadings can be achieved by an optimally designed semi-actively implemented nonlinear damping-based isolation system. Studies including the theoretical investigation and statistical design of a semiactive non-linear damping-based isolation system under various seismic ground motions will be conducted in future studies.

\section{DATA AVAILABILITY STATEMENT}

The datasets generated for this study are available on request to the corresponding author.

\section{AUTHOR CONTRIBUTIONS}

All authors listed have made a substantial, direct and intellectual contribution to the work, and approved it for publication.

\section{ACKNOWLEDGMENTS}

The research work was partly supported by the UK Royal Society (Grant number IE150298). 


\section{REFERENCES}

Amini, F., Mohajeri, S. A., and Javanbakht, M. (2015). Semi-active control of isolated and damaged structures using online damage detection. Smart Mater. Struct. 24:105002. doi: 10.1088/0964-1726/24/10/105002

Dan, M., Ishizawa, Y., Tanaka, S., Nakahara, S., Wakayama, S., and Kohiyama, M. (2015). Vibration characteristics change of a base-isolated building with semi-active dampers before, during, and after the 2011 Great East Japan earthquake. Earthq. Struct. 8, 889-913. doi: 10.12989/eas.2015. 8.4.889

Dan, M., and Kohiyama, M. (2013). "Simultaneous optimization of structural shape and control system of large-scale space frame," in 9th World Conference on Earthquake Resistant Engineering Structures, ERES 2013, A Coruña, 169-178. doi: 10.2495/ERES130141

De Domenico, D., Deastra, P., Ricciardi, G., Sims, N. D., and Wagg, D. J. (2019). Novel fluid inerter based tuned mass dampers for optimised structural control of base-isolated buildings. J. Franklin Inst. 356, 7626-7649. doi: 10.1016/j.jfranklin.2018.11.012

De Domenico, D., and Ricciardi, G. (2018). An enhanced base isolation system equipped with optimal tuned mass damper inerter (TMDI). Earthq. Eng. Struct. Dyn. 47, 1169-1192. doi: 10.1002/eqe.3011

Ebrahimi, B., Khamesee, M. B., and Golnaraghi, M. F. (2008). Design and modeling of a magnetic shock absorber based on eddy current damping effect. J. Sound Vib. 315, 875-889. doi: 10.1016/j.jsv.2008.02.022

Fujita, K., Miura, T., Tsuji, M., and Takewaki, I. (2016). Experimental study on influence of hardening of isolator in multiple isolation building. Front. Built Environ. 2:12. doi: 10.3389/fbuil.2016.00012

Guo, P. F., Lang, Z. Q., and Peng, Z. K. (2012). Analysis and design of the force and displacement transmissibility of non-linear viscous damper based vibration isolation systems. Nonlin. Dyn. 67, 2671-2687. doi: 10.1007/s11071-011-0180-6

Guyomar, D., and Badel, A. (2006). Non-linear semi-passive multimodal vibration damping: an efficient probabilistic approach. J. Sound Vib. 294, 249-268. doi: 10.1016/j.jsv.2005.11.010

Hayashi, K., Fujita, K., Tsuji, M., and Takewaki, I. (2018). A simple response evaluation method for base-isolation building-connection hybrid structural system under long-period and long-duration ground motion. Front. Built Environ. 4:2. doi: 10.3389/fbuil.2018.00002

Ho, C., Zhu, Y., Lang, Z. Q., Billings, S. A., Kohiyama, M., and Wakayama, S. (2018). Non-linear damping based semi-active building isolation system. J. Sound Vib. 424, 302-317. doi: 10.1016/j.jsv.2018.03.023

Kasai, K., Mita, A., Kitamura, H., Matsuda, K., Morgan, T. A., and Taylor, A. W. (2013). Performance of seismic protection technologies during the 2011 Tohoku-Oki earthquake. Earthq. Spectra 29, S265-S293. doi: $10.1193 / 1.4000131$

Kelly, J. M. (1999). The role of damping in seismic isolation. Earthq. Eng. Struct. Dyn. 28, 3-20. doi: 10.1002/(SICI)1096-9845 (199901) 28:1<3::AID-EQE801>3.0.CO;2-D

Kohiyama, M., Omura, M., Takahashi, M., Yoshida, O., and Nakatsuka, K. (2019). Update of control parameters for semi-actively controlled base-isolated building to improve seismic performance. Jap. Archit. Rev. 2, 226-237. doi: $10.1002 / 2475-8876.12090$

Laalej, H., Lang, Z. Q., Sapinski, B., and Martynowicz, P. (2012). MR damper based implementation of non-linear damping for a pitch plane suspension system. Smart Mater. Struct. 21:045006. doi: 10.1088/0964-1726/21/4/045006

Lang, Z. Q., Guo, P. F., and Takewaki, I. (2013). Output frequency response function based design of additional non-linear viscousdampers for vibration control of multi-degree-of-freedom systems. J. Sound Vib. 332, 4461-4481. doi: $10.1016 /$ j.jsv.2013.04.001

Liu, Y. H., and Wu, W. H. (2013). Active vibration isolation using a voice coil actuator with absolute velocity feedback control. Int. J. Autom. Smart Technol. 3, 221-226. doi: 10.5875/ausmt.v3i4.215

Naeim, F. (1989). The seismic design handbook. New York, NY: Springer Science and Business Media. doi: 10.1007/978-1-4615-9753-7

Nakamichi, F. (2018). Control of semi-active oil damper using local sensor for reducing equipment response (master thesis). Keio University, Hiyoshi, Japan.

Peng, Z. K., Lang, Z. Q., Jing, X. J., Billings, S. A., Tomlinson, G. R., and Guo, L. Z. (2010). The transmissibility of vibration isolators with a nonlinear antisymmetric damping characteristic. J. Vib. Acoust. 132:014501. doi: $10.1115 / 1.4000476$

Peng, Z. K., Lang, Z. Q., Zhao, L., Billings, S. A., Tomlinson, G. R., and Guo, P. F. (2011). The force transmissibility of MDOF structures with a non-linear viscous damping device. Int. J. Non-Lin Mech. 46, 1305-14. doi: 10.1016/j.ijnonlinmec.2011.06.009

Sims, N. D., Stanway, R., Peel, D. J., Bullough, W. A., and Johnson, A. R. (1999). Controllable viscous damping: an experimental study of an electrorheological long-stroke damper under proportional feedback control. Smart Mater. Struct. 8:601. doi: 10.1088/0964-1726/8/5/311

Soong, T. (1990). Active Structural Control: Theory and Practice, Ser. Longman Structural Engineering and Structural Mechanics Series. London, UK: AddisonWesley London

Symans, M. D., Charney, F. A., Whittaker, A. S., Constantinou, M. C., Kircher, C. A., Johnson, M. W., et al. (2008). Energy dissipation systems for seismic applications: current practice and recent developments. J. Struct. Eng. 134, 3-21. doi: 10.1061/(ASCE)0733-9445(2008)134:1(3)

Takewaki, I., Murakami, S., Fujita, K., Yoshitomi, S., and Tsuji, M. (2011). The 2011 off the Pacific coast of Tohoku earthquake and response of high-rise buildings under long-period ground motions. Soil Dyn. Earthq. Eng. 31, 1511-1528. doi: 10.1016/j.soildyn.2011.06.001

Taniguchi, M., Fujita, K., Tsuji, M., and Takewaki, I. (2016). Hybrid control system for greater resilience using multiple isolation and building connection. Front. Built Environ. 2:26. doi: 10.3389/fbuil.2016.00026

Taniguchi, T., Der Kiureghian, A., and Melkumyan, M. (2008). Effect of tuned mass damper on displacement demand of base-isolated structures. Eng. Struct. 30, 3478-3488. doi: 10.1016/j.engstruct.2008.05.027

Wang, Y., and Dyke, S. (2013). Modal-based LQG for smart base isolation system design in seismic response control. Struct. Control Health Monitor. 20, 753-768. doi: $10.1002 /$ stc. 1490

Weber, F. (2014). Semi-active vibration absorber based on real-time controlled MR damper. Mech. Syst. Signal Process. 46, 272-288. doi: 10.1016 /j.ymssp.2014.01.017

Conflict of Interest: The authors declare that the research was conducted in the absence of any commercial or financial relationships that could be construed as a potential conflict of interest.

Copyright $\odot 2020 \mathrm{Zhu}$, Lang, Kawanishi and Kohiyama. This is an open-access article distributed under the terms of the Creative Commons Attribution License (CC $B Y)$. The use, distribution or reproduction in other forums is permitted, provided the original author(s) and the copyright owner(s) are credited and that the original publication in this journal is cited, in accordance with accepted academic practice. No use, distribution or reproduction is permitted which does not comply with these terms. 